\title{
Manifestaciones de violencias entre alumnos de educación superior: Los usos del WhatsApp
}

\section{Manifestations of violence among students of higher education: The uses of WhatsApp}

Dr. Luis Antonio Lucio López es Profesor e Investigador de la Universidad Autónoma de Nuevo León (México) (antoniolucio23bu@gmail.com) (https://orcid.org/0000-0002-7287-0967)

Dra. Ma. Teresa Prieto Quezada es Profesora e Investigadora de la Universidad de Guadalajara (México) (materesaprieto@yahoo.com.mx) (https://orcid.org/0000-0002-3299-2927)

Dr. José Claudio Carrillo Navarro es Profesor e Investigador de la Universidad de Guadalajara (jccn1964@gmail.com) (https://orcid.org/0000-0002-5320-7545)

Recibido: 2017-12-12 / Revisado: 2018-05-20 / Aceptado: 2018-05-24 / Publicado: 2018-07-01

\section{Resumen}

En este artículo se presentan resultados de una investigación sobre algunas manifestaciones de violencia a través de WhatsApp entre alumnos de Educación Superior, realizada en II programas educativos. Conocer los nuevos tipos de maltratos que hacen y sufren a través de WhatsApp los alumnos de facultad inscritos en una universidad pública de la ciudad de Guadalajara, Jalisco, México. Fueron encuestados 54I alumnos(as) en una muestra probabilística de una población de 17000 estudiantes, trabajando con un 95\% de nivel de confianza para estimar una proporción por medio de un intervalo bilateral con un enfoque conservador obteniendo un límite de error de .04I (4.1\%).
Entre los resultados más relevantes encontramos que un 48\% de la muestra se ha sentido incómodo y disgustado por fotografías pornográficas que le han enviados sus contactos sin haberlas solicitado y sin que le notificaran del envío de estas imágenes; los mismo ocurre con un $37.4 \%$ de la muestra con alumnos(as) a los que enviaron videos pornográficos. Este tipo de mensajes constituyen nuevos maltratos que ofenden a quienes los reciben, como ocurre además con un 18.7\% del alumnado a quienes les han hechos memes aparentemente inofensivos, pero que hacen sufrir a quienes en ellos aparecen al ser ridiculizados. Otro hallazgo importante, fue el relacionado con la indiferencia y cómo está se ha convertido en nuevo tipo de violencia que sufren un $77.8 \%$ de alumnos.

Forma sugerida de citar: Lucio López, L. A., Prieto Quezada, M. T., \& Carrillo Navarro J. C. (2018). Manifestaciones de violencias entre alumnos de educación superior: Los usos del WhatsApp. Alteridad, 13(2), 204-213. https://doi.org/10.17163/ alt.v13n2.2018.04 
Descriptores: Violencia, alumnos, redes sociales, WhatsApp, ciberbullying.

\begin{abstract}
In this article we present the results of an investigation regarding violence demonstration through WhatsApp among students of Higher Education, carried out in I I educational programs. To learn the new types of mistreatment that faculty students enrolled in a public university in the city of Guadalajara, Jalisco, Mexico do and suffer through WhatsApp. 54I students were surveyed as part of a probabilistic sample of a population of 17000 students, working with a 95\% confidence level to estimate a proportion by means of a bilateral interval with a conservative approach obtaining an error limit of. 04I (4.1\%).
\end{abstract}

\section{Introducción}

Para nadie es un secreto que adolescentes y jóvenes dedican la mayor parte de su tiempo a actividades relacionadas con el uso de internet. Están en la llamada Red de redes a cada momento entrando y saliendo intermitentemente y en ese continuo ir y venir parecen vivir dos vidas, una en la realidad presencial y otra en la realidad virtual. Como afirman Area, Borrás y San Nicolás (2015) es notorio que sus modos de consumo, producción y difusión con relación a la cultura representan una ruptura con los usos y costumbres de su familia y entorno, ya que sus relaciones entre pares, familia y escuela, actualmente está mediado por interacciones online, con los cuales ellos socializan y dan su cara al mundo.

Las redes sociales han permitido visibilizar a los jóvenes y socializar sus modos de vida, el uso de internet se ha vuelto un modus vivendi para una gran cantidad de usuarios. En este contexto de presencia del mundo digital y realidad aumentada (Ortega-Ruiz, Del Rey y Sánchez, 2012, p. 45) es decir, las redes sociales juegan un lugar importante y fundamental como factor de socialización para los jóvenes, estando a la par de los amigos, la familia y los espacios escolares, otrora factores esenciales en la generación de
Among the most relevant results, we found that $48 \%$ of the sample has felt uncomfortable and disgusted by pornographic photographs that their contacts have sent without their consent; the same happened with $37.4 \%$ of the sample of students to whom pornographic videos were sent. These types of messages constitute new abuses that offend those who receive them, which is also the case for $18.7 \%$ of the students who have been targets of seemingly harmless memes, however, those who appear in them suffer ridiculing. Another important finding was the one related to indifference and how it has become a new type of violence suffered by $77.8 \%$ of students.

Keywords: Violence, students, social networks, WhatsApp, cyberbullying.

convivencia del individuo. Convivencia que estaba regulada y quizás vigilada por los padres de familia en el entorno hogareño y por los docentes en el ámbito escolar.

La comunicación digital, al ser mediada por dispositivos electrónicos de uso personal como los teléfonos móviles, las tabletas y los ordenadores, transcurre a distancia de la atención de los adultos y cercana a los iguales que se encuentran hiperconectados en espacios escolares. En este marco, en el que se desarrollan los alumnos se están aprendiendo formas de violencia que no pueden ser desconocidas, por los padres y educadores, considerando que la escuela ocupa un espacio central para que los estudiantes aprendan a vivir juntos y de forma pacífica.

\subsection{Antecedentes. Algunos fundamen- tos teórico metodológicos}

Existen actualmente una multiplicidad de manifestaciones de violencia, que, ahora objetivados mediante el uso de las distintas redes sociales, proveen de nuevos rostros y formas de comunicación entre los jóvenes, con otros lenguajes y formas de comunicación, que a través de las tecnologías de la información adquieren particularidades en torno los impactos y conse- 
cuencias en los sujetos estás formas de interacción virtual. Han surgido un sinnúmero de fenómenos y situaciones, que difícilmente permiten contar con inventario definitivo y acabado, lo que si es factible detectar es que estos representan la metamorfosis de procesos relacionados con diversas situaciones de acoso, violencia y agresión, ahora, con la utilización de distintos dispositivos digitales y una gama heterogénea de aplicaciones tecnológicas.

En los últimos años ha surgido una nueva forma de agresión, a menudo denominada ciberacoso, en donde la agresión se produce a través de medios informáticos y, más específicamente a través de teléfonos móviles y de internet (Smith, 2006).

Este investigador definió ese fenómeno como ciberacoso destacando que éste "es un acto agresivo e intencionado llevado a cabo de manera repetida y constante a lo largo del tiempo, mediante el uso de formas de contacto electrónicas por parte de un grupo o de un individuo, contra una víctima que no puede defenderse fácilmente". Cabe destacar que entre los tipos de ciberacoso, subrayo los mensajes de texto, intimidación telefónica, intimidación a través de fotografías y videos; asedio por correos, asedio por sesiones de chat, intimidación a través de programas de mensajería instantánea y asedio vía páginas web.

Con el paso del tiempo se encontró que el fenómeno del bullying estaba muy relacionado con el acoso cibernético, al descubrirse que, en el ámbito académico, los agresores escolares continuaban en el ciberespacio los maltratos, considerando así que este este era un bullying indirecto. Desde esta perspectiva autores como Hinduja y Patchin (2008) establecieron que el ciberbullying era producto de una infortunada unión del bullying con la comunicación electrónica y la telefonía móvil.

Una de las predisposiciones que actualmente tiende a prevalecer de manera análoga en los usos de la telefonía móvil, de manera particu- lar a través del uso de los smartphone y iPhone para desarrollar procesos de acoso entre los jóvenes, ha sido documentada a través de distintos estudios implementados en diversas latitudes.

En el caso de España, Calmaestra (2011) realizó un estudio en Córdoba con una muestra de 1671 alumnos de secundaria encontrando que un $8.3 \%$ de la muestra había sido maltratada a través de teléfono móvil. De igual manera, otro trabajo desarrollado en el mismo país, Del Río, León, Castaño y Gómez, realizaron una investigación en la comunidad de Extremadura encontrando que un $8.8 \%$ de una muestra de 620 estudiantes de quinto y sexto año de primaria, había sido acosado a través de teléfono móvil.

En México, Velázquez Reyes (2010) realizó una investigación con una muestra de 594 alumnos de secundaria y 31 alumnos de licenciatura, encontrando un $10.5 \%$ de cibervíctimas, Lucio López y González González (2012) realizaron un estudio entrevistando mil 66 alumnos de 28 escuelas preparatorias, encontrando que un $49.9 \%$ de la muestra habían recibido insultos a través de telefonía móvil, un $18 \%$ habían sido víctimas de amenazas, un 9.7\% habían sido víctimas de chantaje; un 9.8\% recibió mensajes de acoso sexual, $15.8 \%$ fue afectado su reputación y dignidad 7.6\% fue víctima de compañeros que le tomaron videos y los distribuyeron para ridiculizarlos.

Los datos ofrecidos anteriormente, nos muestran ciertas analogías estructurales de las tendencias que por el momento se están desarrollando en diferentes regiones del planisferio en cuanto la utilización creciente de expresiones, conductas y comportamientos vinculados con situaciones de agresión y violencia mediante los dispositivos lo que nos muestra la magnitud que el fenómeno ha ido adquiriendo por lo que resulta de fundamental importancia su comprensión y explicación.

Un antecedente clave en el presente estudio es la investigación realizada por nosotros mismos, Prieto, Carrillo y Lucio (2015) en este mismo espacio educativo, donde desarrollamos un análisis desde una perspectiva más amplia, 
para identificar las situaciones de bullying y ciberbullying en este mismo espacio escolar.

En esta investigación a diferencia de la anterior, se pretende hacer notorios aspectos ligados a los jóvenes, en su vínculo (en este caso, nocivo) a través de las Tecnologías de la Información y la Comunicación (TIC) la información y comunicación, es el elemento fundamental que considerar, por su rol e influencia a nivel cultural y, en particular, en el aspecto educativo. Ente los hallazgos más importantes encontrados, se lograron identificar de manera significativa los usos relacionados con la aplicación del Whatsapp, como uno de los medios de comunicación más comunes en el contexto de la comunidad estudiantil para desarrollar diversas manifestaciones de agresión y violencia.

\subsection{Orígenes y nuevos usos de WhatsApp}

El WhatsApp nace en el año 2009 creada por Jan Koum director de equipo de operaciones de Yahoo (Moreno, González, Torres y Hernández, 2017) estas autoras señalan que el nombre original era What's up ¿Qué pasa? Y app (aplicación) esta herramienta creció en poco tiempo con gran éxito y popularidad entre los usuarios, con una multiplataforma sencilla de usar, ya que toma los datos de las personas.

Se podría resaltar que uno de las inconvenientes de esta aplicación, es que toda la información se envía en texto, sencillo, con lo que, cualquier persona con algo de conocimiento en esta red social, puede entrar y hacer uso incorrecto de la misma. El cuidado de lo que se comparte en redes sociales es fundamental. Uno de los principales riesgos que entraña WhatsApp, es el uso que les puede dar a esta red social, como es el hecho de que se presentan muchas posibilidades entre los jóvenes usuarios de que publiquen; mensajes, fotos y videos con palabras y/o imágenes comprometedoras que les permite a los agresores, extorsionar, maltratar o ridiculizar, con memes, burlas, o escarnio, entre otros. En términos generales, no existen todavía de manera suficiente, marcos normativos y legales que regulen o controlen las manifestaciones de procesos de violencia en las diversas aplicaciones tecnológicas utilizadas como medio de comunicación, lo que hace más frágil sus diversos usos, el Whatsapp no es la excepción.

\subsection{Nuevas violencias}

Uno de los maltratos emergentes que en WhatsApp se han presentado, es el envío de fotografías y videos pornográficos a contactos que no la solicitaron y a los que no se les aviso del contenido de estos mensajes. En México se han dado casos de personas que, al terminar una relación de pareja, suben a la red videos o fotografías de sus parejas como forma de venganza causando un enorme daño moral, físico y psicológico a las víctimas. Ante ello la senadora Mónica Arriola Gordillo (2015) propuso una iniciativa para reformar el Código Penal Federal a fin de sancionar el delito de abuso que se comete cuando una persona fotografía o graba la imagen de otra, parcial o totalmente desnuda, y la distribuye en cualquier medio sin su consentimiento, de forma impresa o en las redes sociales.

Uno de los formatos que recientemente se han convertido en uso común mediante la utilización de las redes sociales para desarrollar manifestaciones con propósitos de ridiculización, daño, diversas formas de sarcasmo e incluso deterioro de la imagen de algún evento o personaje son los llamados "memes". Dawkins (1993, p. 218) acuñó a mediados de años setenta el concepto de "meme" en su libro "El gen egoísta" y las concibió como ideas culturales que se trasmitían de cerebro a cerebro y de generación en generación. Estos podrían ser la imitación de una tonada "pegajosa" por llamarla de algún modo, sones, consignas, modas en cuanto a vestimenta, formas de construir vasijas o de construir arcos. Con el paso del tiempo el concepto ha cambiado son memes ahora fotografías, videos, dibujos formas gráficas que aparentan ser vehículos de buen humor, pero que esconden la burla y la ridiculización. Se han convertido en un maltrato 
emergente en las redes sociales y puede ser dirigido a individuos, grupos y hasta organizaciones.

De acuerdo con Hernández (2016) un meme es un término técnico con el que se llama a una especie de modas recurrentes de internet, cuya característica es la tendencia a crear viñetas con ciertas caras dibujadas y cuyo origen no es sólo un autor, sino que es un producto surgido de una comunidad denominada 4chan en el que inició todo este fenómeno. Hoy esas viñetas iniciales han sido cambiadas por fotos tomadas furtivamente o tomadas de algún álbum fotográfico de la red, con la intención de ridiculizar a quienes en ellas aparecen.

Montero (2016) define meme como los montajes de imagen y texto que hoy circulan por internet, cuyo fenómeno ha tomado dimensiones desbordantes, que más allá del humor y la anécdota, ha dinamizado la relación entre producción y circulación de imágenes. La autora hace énfasis en que existe primero una apropiación de una imagen que luego es transformada a través de un fotomontaje. Es decir, una foto es tomada con su forma original y luego es trasformada por el autor o por otros. Azahua (2014) señala que existe violencia cuando se toma una o varias fotografías sin el consentimiento del retratado. La cámara -afirma- trabaja en contra de la voluntad del retratado. Arango (2014) señala que actualmente en la cultura digital, los memes son entendidos como cualquier texto, imagen o video -con cierto sentido humorístico- que se comparte en las redes sociales, pero advierte que los sujetos involucrados reinterpretan definiciones de la realidad, creando sus propios significados. Es decir, quien hace un meme trasforma una imagen construyendo una nueva desde su propia subjetividad. Así, quien crea un meme, puede llegar a pensar que está haciendo algo divertido, cuando en realidad hace daño y, por tanto, genera violencia.

Otro fenómeno que ha venido adquiriendo status y hemos reconocido como una forma simbólica de maltrato o violencia con la utilización de la aplicación del WhatsApp es: la indiferencia. El dejar "en visto" el ignorar los mensajes del contacto con quien se lleva una comunicación, causa malestar en quien se siente ignorado. La investigadora Ianire Estébañez (2016) señala que este tipio de conductas puede ser considerada como violencia pasiva, pues produce daño con aquello que no hace, pues la persona que sufre la indiferencia es dañada psicológicamente, sobre todo en su autoestima, pues la hace sentir que no es valiosa o importante.

\subsection{De la tranquilidad al desasosiego}

En definitiva (Ortega-Ruiz, Del Rey y Sánchez, 2012, p. 46):

El espacio cibernético se ha convertido en un escenario de intercambio, no solo de información, sino particularmente de imágenes, muchas muy personales, como fotografías de momentos emotivos y hechos relevantes que podrían comprometer la intimidad de los protagonistas.

Con los dispositivos electrónicos y aplicaciones de mensajería instantánea como WhatsApp los alumnos amplifican sus redes sociales incluyendo amistades y enemistades, en ellas viven momentos de alegría, pero también de desasosiego porque desgraciadamente se dan casos de abusos, intimidación, falta de respeto acoso y agresiones injustificadas.

La investigación que hemos desarrollado tiene el objetivo de conocer el uso que hacen los estudiantes de educación superior de los diversos programas educativos del Centro Universitario de la Universidad de Guadalajara mediante la Red Social WhatsApp y la incidencia de viejos y nuevos maltratos, mismos que puedan estar vinculados con el fenómeno conocido como ciberbullying.

\section{Metodología}

Esta investigación es descriptiva y transversal, el propósito es describir la convivencia del alumnado en WhatsApp y los usos que hacen de esta aplicación, en el marco de comportamientos 
se encuentran identificados con el fenómeno del ciberbullying.

\subsection{Participantes}

Los participantes son 541 alumnos de una población de 17000 estudiantes de un centro universitario de una universidad pública de la ciudad de Guadalajara, Jalisco en México. La muestra es probabilística trabajando con un nivel de confianza de $95 \%$ para estimar proporción por medio de un intervalo bilateral con un enfoque conservador obteniendo un límite de error de .041 (4.1\%). La muestra estuvo integrada por un $45.6 \%$ de hombres y un $54.4 \%$ de mujeres, su edad fue de 18 a 26 años, aunque hubo dos casos de personas de $40 \mathrm{y}$ 43 años, por ser alumnos de licenciatura.

\subsection{Instrumento}

Se utilizó un cuestionario en forma de auto-informe construido exprofeso para esta investigación inspirado en el instrumento utilizado por Calmaestra y Ortega-Ruiz y el utilizado por el Defensor del Pueblo de Madrid, cuya confiabilidad fue validada en sus estudios de bullying y ciberbullying.

\subsection{Recogida de datos y codificación}

Una vez obtenida la muestra acudimos con los directivos responsables de los 11 Programas Educativos de Educación Superior del Centro Universitario con el propósito de generar las condiciones básicas para facilitar el proceso de investigación y comunicar las intenciones y propósitos del trabajo a realizar. Posteriormente seleccionamos la muestra y hablamos con los participantes explicándoles el motivo de la indagación, hacien- do énfasis en que el instrumento era anónimo solicitando respondieran con sinceridad, pues ningún caso sería tratado en lo individual. Al final del cuestionario los alumnos firmaron un apartado dando su consentimiento de participación en la investigación, en el entendido que cada uno de ellos tenían la mayoría de edad. Participaron alumnos del primero al décimo semestre.

Los participantes tardaron entre 20 y 25 minutos en contestar el auto-informe y fue entregado a un representante de los alumnos, quien los depositó en el escritorio del profesor. En la aplicación participaron los tres investigadores, quienes recogieron los cuestionarios. Una vez que contamos con los 541 cuestionarios procedimos a la captura de las respuestas en el programa estadístico SPSS versión 21.

\section{Análisis y resultados}

De los hallazgos más sobresalientes encontramos información desagregada en diferentes rubros: promedio de conexión, horarios, rol de víctima, rol de agresor.

\subsection{Promedio de conexión}

El promedio de conexión fue de 7 horas entre semana y de 9 horas los fines de semana. En cuanto al tema de la adicción a WhatsApp, un 71.3 de la muestra señaló que la aplicación es adictiva, sin embargo, solo un $34.3 \%$ dijeron haber desarrollado una especie de adicción a WhatsApp.

En cuanto a sus horarios de conexión, encontramos que los alumnos están conectados la mayor parte del día, aún en horarios de clases, y que por lo menos uno de cada dos navega de madrugada, según se puede apreciar en la siguiente tabla.

Tabla 1. Horarios de conexión

\begin{tabular}{|l|l|l|l|}
\hline \multicolumn{1}{|c|}{ En cuáles de los siguientes horarios usas WhatsApp } & Nunca & Algunas veces & Muchas veces \\
\hline 1.- De 5 a 9 de la mañana & $24 \%$ & $63.1 \%$ & $12.9 \%$ \\
\hline 2.- De 10 de la mañana a 2 de la tarde & $8.2 \%$ & $53.1 \%$ & $38.7 \%$ \\
\hline 3.- De 3 a 7 de la tarde & $5.7 \%$ & $37.2 \%$ & $57.2 \%$ \\
\hline
\end{tabular}


Como se puede apreciar en la tabla 1, ya no hay un horario especial de conexión, pues los alumnos están conectados a cualquier hora, incluso de madrugada pues un $5.4 \%$ de la muestra informó que frecuentemente navega de 1 a 4 de la madrugada.

WhatsApp se ha convertido en una aplicación clave, en la comunicación y convivencia de los estudiantes de este centro universitario, toda vez que un $29.3 \%$ de la muestra señaló que la aplicación es Muy importante en su vida, un 63.5 considero que es Algo importante y un 7.2\% consideró que WhatsApp es Nada importante. Esto se debe a que están integrados en grupos de comunicación que tienen que ver con sus compañeros de escuela (97.6\%) para estar al tanto de tareas y otras actividades académicas, también están en grupos de amigos (93.6\%) para actividades de entretenimiento y en grupos de familia $(59.3 \%)$ para estar en contacto con sus seres queridos.

\subsection{Los maltratos en WhatsApp. Las víctimas}

En cuanto a los maltratos en WhatsApp podemos observar que el ser ignorado es el maltrato que presenta mayor incidencia, pues casi seis de cada diez alumnos lo sufren, seguido de las palabras ofensivas, los insultos y las ridiculizaciones. Vemos que emerge un nuevo maltrato que es la elaboración de memes con la imagen de la víctima, que dañada con mensajes de aparentes bromas.

\section{Tabla 2. Los maltratos a las víctimas}

\begin{tabular}{|c|c|c|c|}
\hline $\begin{array}{l}\text { Tú en lo personal, en WhatsApp ¿has sido víctima de alguna } \\
\text { de las siguientes conductas de parte de alguno de tus contactos? }\end{array}$ & Nunca & $\begin{array}{c}\text { Algunas } \\
\text { veces }\end{array}$ & $\begin{array}{c}\text { Muchas } \\
\text { veces }\end{array}$ \\
\hline 1.- ¿Te han insultado? & $64.9 \%$ & $29.6 \%$ & $5.5 \%$ \\
\hline 2.- ¿Te han amenazado? & $90.2 \%$ & $8.7 \%$ & $1.1 \%$ \\
\hline 3.- ¿Te han ridiculizado? & $81.7 \%$ & $15.9 \%$ & $2.4 \%$ \\
\hline 4.- ¿Te han escrito palabras que te han ofenden? & $58.6 \%$ & $37.3 \%$ & $4.1 \%$ \\
\hline 5.- ¿Han dicho frases que le han hecho sentirse acosada(o) sexualmente? & $69.1 \%$ & $27.2 \%$ & $3.7 \%$ \\
\hline 6.- ¿Te han hecho memes con tu imagen a fin de ridiculizarte? & $81.3 \%$ & $16.3 \%$ & $2.4 \%$ \\
\hline 7.- ¿Te han tomado videos sin tu consentimiento con el fin de ridiculizarte? & $87.6 \%$ & $11.5 \%$ & $0.9 \%$ \\
\hline 8.- ¿Te han enviado mensaje de voz ofensivos con violencia verbal? & $87.2 \%$ & $11.5 \%$ & $1.3 \%$ \\
\hline 9. ¿Te han ignorado? & $22.2 \%$ & $58.4 \%$ & $19.4 \%$ \\
\hline
\end{tabular}


Otro maltrato que emerge es el envío de imágenes pornográficas que han recibido sin solicitar y sin que les hayan avisado del contenido un $48 \%$ de la muestra, es decir casi dos de cada dos estudiantes de la muestra. Lo mismo ocurre con un $37.4 \%$ de la muestra, quienes han recibido videos pornográficos sin haberlos solicitado y sin saber el contenido de lo que se le enviaba.

En pregunta abierta los alumnos mencionaron que eso les hizo sentir incómodos, disgustados por haberlas visto. Entre el material que les llegó había videos de pornografía, fotos obscenas con imágenes muy perturbadoras. $\mathrm{Y}$ eso, según sus respuestas, ocurrió en los tres meses anteriores a la entrevista.

\subsection{Los agresores}

El cuestionario permite expresar si ellos cometieron algunos de esos maltratos, identificándose en el rol de agresores. Los resultados nos hablan de la comisión que el mayor maltrato es ignorar los mensajes el otro, pues nos habla de que casi 8 de cada diez alumnos ha vuelto una práctica común la indiferencia, convirtiéndola en un nuevo tipo de violencia. Los resultados no varían mucho a los que dicen haber recibido las víctimas, por lo que se confirma que el mal uso de la aplicación de WhatsApp está afectado la convivencia de los alumnos del Nivel Superior, donde es de suponer que el índice de maltratos debe ser bajo.

Tabla 3. Los agresores

\begin{tabular}{|c|c|c|c|}
\hline $\begin{array}{c}\text { En WhatsApp ¿has sido realizado alguna de las siguientes } \\
\text { conductas en contra de alguno de tus contactos? }\end{array}$ & Nunca & $\begin{array}{l}\text { Algunas } \\
\text { veces }\end{array}$ & $\begin{array}{l}\text { Muchas } \\
\text { veces }\end{array}$ \\
\hline 1.- ¿Lo has insultado? & $64.7 \%$ & $30.1 \%$ & $5.2 \%$ \\
\hline 2.- ¿Lo has amenazado? & $94.3 \%$ & $4.8 \%$ & $0.9 \%$ \\
\hline 3.- ¿Lo has ridiculizado? & $74.3 \%$ & $21.6 \%$ & $4.1 \%$ \\
\hline 4.- ¿Has escrito en su muro palabras que lo ofenden? & $88.5 \%$ & $9.8 \%$ & $1.7 \%$ \\
\hline 5.- ¿Le has escrito frases que lo han hecho sentirse acosado(a) sexualmente? & $93 \%$ & $4.6 \%$ & $2.4 \%$ \\
\hline 6.- ¿Has hecho memes con su imagen con el fin de ridiculizarlo? & $78.6 \%$ & $17.2 \%$ & $4.3 \%$ \\
\hline 7.- ¿Le has tomado videos sin su consentimiento a fin de ridiculizarlo? & $81.5 \%$ & $16.3 \%$ & $2.2 \%$ \\
\hline 8. ¿Le has enviado mensajes de voz ofensivos conteniendo violencia verbal? & $86.7 \%$ & $10.2 \%$ & $3.1 \%$ \\
\hline 9. ¿Lo has ignorado? & $22.7 \%$ & $53.6 \%$ & $23.7 \%$ \\
\hline
\end{tabular}

El ítem 9 de la tabla 3 nos corrobora de manera fehaciente cómo el tema relacionado con la indiferencia de los mismos agresores se ha convertido en un comportamiento que empieza a caracterizar como otra vertiente o rostro de una forma de exclusión, al ignorar a los sujetos, cuando manifiestan hacerlo algunas veces el 53\% y Muchas veces el 23\%. La marginación de los sujetos en estos contextos de interacción comunicativa virtual, en este caso a través de Whatsapp genera un sentimiento por parte de quien es victimizado, de omisión y vacío, que impacta de manera significativa en su perfil emocional.

\section{Discusión y conclusiones}

En aspectos que para nosotros resultan significativos es el hecho de encontrar maltratos emergentes, que van surgiendo con el paso del tiempo como es la indiferencia, que si bien es frecuente en la realidad presencial, ahora viaja al ciberespacio y navega en los mensajes "dejados en visto" en WhatsApp, otro hallazgo es el hecho de que los memes se convierten en instrumento de violencia, al ser distribuidos en esta red social, con la aparente estructura de una broma más, pero que causa mucho daño a quien aparece como 
protagonista en fotos que le fueron hurtados de su perfil, su álbum o que le fueron tomadas furtivamente en imágenes de videos o fotografías. Una imagen tomada sin consentimiento es un acto de violencia. La pornografía resulta incómoda, disgusta a quien no la solicita y le llega al receptor un ámbito que se supone es privado e íntimo. Por esa razón debe ser considerado un maltrato, pues además pone en riesgo la libertad de quien la recibe sin consentimiento, toda vez que las policías cibernéticas están al acecho de la circulación de material prohibido en los códigos penales del mundo.

Como afirman Area Moreira, Borrás Machado y San Nicolás Santos (2015) es momento en que los padres, profesores y sociedad, debemos tomar cartas en el asunto, ver los claro y sombrío de las redes sociales, donde los adultos jugamos un papel fundamental para guiar a nuestros hijos y alumnos en la buena conducta digital, en la construcción de una identidad digital sana que no ponga en peligro su reputación, su privacidad y su seguridad. La escuela tiene que poner su aporte, debe adaptar el currículo a los nuevos tiempos, cualquier reforma en el campo educativo deben contemplar el desarrollo de habilidades para la convivencia en el ciberespacio y propiciar una cultura para el buen manejo de internet que beneficie a una sociedad digital.

De ahí que como afirma el filósofo italiano Luciano Floridi (2018):

Necesitamos que las redes sociales conduzcan el impacto ético de las tecnologías de la información y comunicaciones en nosotros y nuestro ambiente. Necesitamos que mejore la dinámica económica, social y política de la información.... necesitamos que la filosofía desarrolle el marco intelectual correcto para ayudarnos a darle significado y entender nuestra nueva situación. ...Necesitamos una filosofía de la información como la filosofía de nuestra época para nuestra época.

Los usos de las redes sociales, sus lógicas de producción, consumo y comunicación requieren nuevos marcos éticos, jurídicos, axiológicos y educativos que permitan regular las nuevas y emergentes interacciones comunicativas de nuestra época. El desarrollo de las tecnologías requiere de formas específicas de reflexión epistemológica y filosófica que nos posibiliten marcos de comprensión sobre la diversidad de implicaciones de lo que atinadamente ha llamado Floridi "la época de la infoesfera", ya que ella, está remodelando y transformando la realidad humana.

\section{Referencias bibliográficas}

Area Moreira, M., Borrás Machado, J.F., \& San Nicolás Santos, M.B. (2015). Educar a la generación de los Millennials como ciudadanos cultos del Ciberespacio. Revista de Estudios de Juventud, 13-32.

Arango, L.G. (2014). Estrategia en el uso de los memes como estrategia didáctica en el Aula. Ponencia presentada en el Congreso Iberoamericano de Ciencia y Tecnología. Buenos Aires, Argentina.

Arriola, M.T. (2015). Iniciativa de Ley en materia de violación a la privacidad y correcto desarrollo psicosexual de las personas. Gaceta Senado de la República. México. Documento en la red recuperado el 6 de julio de 2017. Recuperado de: https://goo.gl/TEuTBM

Azahua, M. (2014). Retrato involuntario. El acto fotográfico como forma de violencia. México: Ed. Tusquets.

Buelga, S., Cava, M.J. y Musitu, G. (2010). Cyberbullying: victimización entre adolescentes a través del teléfono móvil y de Internet. Psicothema, 22(4), 784-789

Calmaestra, J. (2011). Cyberbullying: Prevalencia y características de un nuevo tipo de bullying indirecto. (Tesis Doctoral). Universidad de Córdoba.

Dawkins, R. (1993). El gen egoísta: España: Salvat.

Estébañez, I. (2016). Dejar en visto en WhatsApp; la indiferencia como violencia en red. Recuperado de https://goo.gl/U8WLb5

Finkelhor, D. Mitchell, K.J. y Wolak, J. (2000). Online Victimization: A report on the Nation's youth. National Center for Missing 
an Exploited Children. Recuperado de: https://goo.gl/Mbq6Ab

Floridi, L. (2018). Llegamos a la infoesfera... y ahora, ¿qué hacemos? El Comercio Entrevista, Perú. Recuperado de: https://goo.gl/8NVNce

Hernández, R. (2016). 11 memes recurrentes. Recuperado de https://goo.gl/HsaQVC

Hinduja, S. y Patchin, J.W. (2008). Cyberbullying an exploratory analysis of factors related to offending and victimization. Deviant Behavior, 29(2), 129-156.

Lucio, L.A. y González, H. (2012). El teléfono móvil como instrumento de violencia entre estudiantes de bachillerato. Ponencia presentada en el IV Congreso Latina de Comunicación. Tenerife, España.

Montero, V. (2016). Fotografía desobediente y bastarda. Del fotomontaje político a los memes. Recuperado de: https://goo.gl/S1YC9y

Moreno López, Nidia, González, Robles, Angie, Torrez Gómez, Ana \& Anaya Hernández,
Julissa (2017). Alfabetización digital a padres de familia en el uso de las redes sociales. Alteridad 12(1), 8-19.

Ortega-Ruiz, R., Del Rey, R. y Sánchez, V. (2012). Nuevas dimensiones de la convivencia escolar y juvenil. España: Ministerio de Educación y Deporte.

Prieto, M.T, Carrillo J.C, y Lucio L. (2015). Violencia virtual y acoso escolar entre estudiantes universitarios: el lado oscuro de las redes sociales. México. Revista Innovación educativa, 15(68), 33-47. Recuperado de: https://goo.gl/v7GtRN

Smith, P.K. (2006). Ciberacoso: naturaleza y extensión de un nuevo tipo de acoso dentro fuera de la escuela. Ponencia presentada en el Congreso de Educación Palma de Mallorca.

Velázquez, L.M. (2010). Adolescentes en tiempos de oscuridad: violencia social online en estudiantes de secundaria. Toluca, México: ANEFH. 